\title{
EL JUEGO Y LA RECREACIÓN COMO MEDIOS DE SOCIALIZACIÓN
}

\section{Propuesta de grado*}

\section{Omar Alberto Mossos Chaves Condensado por: Francisco Beltrán $P$.}

La investigación es la tarea básica que identifica a la vida académica. En el caso de la Educación Física la investigación aparece como su mayor reto. Este apenas comienza a afrontarse, lo cual resulta formidable, a la vez que reconfortante. Lógico, la investigación no es una flor silvestre. Requiere esmero dentro de un clima propicio. Su caldo de cultivo se encuentra en la atmósfera de las inquietudes constantes, del cuestionamiento ininterrumpido, de la problematización transdisciplinal, de la crítica exigente, del juego del saber, de la curiosidad insatisfecha, de la lúdrica de la humanización.

Si se pretende determinar el proceso de la investigación en Educación Física en el país, se debe buscar su avance en los trabajos degrado de los respectivos Departamentos y en las ponencias presentadas en los foros académicos. En este caso se trata de confrontarlo en el primer espacio señalado. A ello responde este condensado.

La propuesta pedagógica de la referencia resulta significativa por la importancia del tema abordado; por la sugestividad del enfoque de la Educación Física asumido como alternativa pedagógica; por la originalidad en la apropiación metodológica, por la lozanía en el cuestionamiento, en la búsqueda y en la problematización; por el acercamiento al análisis, a la reflexión y a la crítica; por el nivel de Práctica Pedagógica y Didáctica interactuada con, por, desde y para la comunidad; por el compromiso profesional establecido como agente de cambio sociocultural.

Todo lo cual permite configurar esta propuesta como un prototipo de investigación participante, digno de ser tenido en cuenta a fin de avanzar en esta línea investigativa, no en cuanto modelo acabado sino por el paradigma asumido. Lo importante es empezar, indica el saber popular. Quizás sea cierto. Para la muestra un botón, agrega dicho saber. Es así como se visualiza la búsqueda teórico- práctica y operativa de la Educación Física en cuanto proyecto pedagógico alternativo en aras de dar respuestas a una sociedad defraudada por la razón monológica instrumental. Se trata entonces de la apertura de la razón dialógica participativa-alteridad-, lúdrica matinal de la humanidad.

El autor expone la síntesis del proceso de articulación de su propuesta. Como es obvio el punto de partida lo ubica en las observaciones concienciadas, en las preguntas formuladas, en las lecturas realizadas sobre el tema, en las muchas horas de trabajo y de reflexión, con una preocupación de fondo: en qué medida podía contribuir al cambio en el trabajo del educador físico, así como en su concepción de la vida. Una cita de José Martí le permite prender el faro: Los hombres son como los astros, unos dan luz de sí y otros brillan con la luz que reciben.

Un taller con el grupo base le permite identificar los problemas y reales necesidades existentes, lo cual nutre el cuestionamiento recíproco - del investigador-posibilitador como del grupo -, suscita la reflexión, el diálogo y la creatividad. El reto aparece cuando se encuentra con el "fracaso" de la estrategia empleada: constatar con evidencias que el

\footnotetext{
* Presentada al Dpto. de E. F. de la U.P.N. en Dic. de 1990. 
deporte conlleva competencia generadora de agresividad y en vez de cohesionar al grupo, produjo el efecto opuesto. Los "fracasos" en investigación constituyen su fuente de enriquecimiento. Si no es el deporte el medio indicado entonces, ¿cuál es su alternativa? Desde luego: el juego y la recreación. ¡Eureka! ¿Por qué razones? ¿El hombre es básicamente competencia y agresividad; o es un ser juguetón, lúdrica en suma? En todo caso el faro hay que alimentarlo para que no se extinga:

Si tienes mucho, da mucho; Si tienes poco, da poco pero da siempre, ya que un hombre con pereza es un reloj sin cuerda.

Balmes.

El juego se lo suele considerar como un lugar común. ¿Tal apreciación significa que se lo conoce en su naturaleza, importancia, sentido y trascendencia? O por el contrario, ¿indica más bien su total desconocimiento? ¿ Se lo estudia e investiga? ¿Cuáles son sus teorías? ¿Cuál el debate entre ellas en la articulación del juego como estrategia pedagógica? ¿Se lo cultiva, a la vez que se posibilita su cultivo? ¿Por qué razones se deja de lado el juego lúdrico (perdón por la redundancia), para imponer el juego, de la competencia, de la rivalidad, de la agresividad, de la intransigencia, del tener sacrificando al ser, de la mecanización esclavizante? ¿Cómo devolverle el juego ala vida humana?, ¿Por qué el juego no es el elemento básico de la educación, de la cultura, de la pedagogía, de la vida? ¿Por qué no emplear el juego como posibilitador de socialización, por ende de aprendizaje creativo y de producción de conocimiento? Acaso, ¿hay algo más serio que el juego? Parece que el juego conduce al arte y éste constituye la mayor satisfacción humana.

¿Qué decir con respecto a la recreación y a sus innumerables posibilidades? Imposible pretender agotar las preguntas. No se trata de ello, sino de suscitarlas. Expresivo texto anotado por el autor al respecto al intensificar la luz del faro:

Seis sabios servidores me enseñaron cuanto sé; sus nombres son: cómo, cuándo, dónde, qué, quién y por qué.

Kipling

Los méritos de la propuesta en manera alguna exoneran a la crítica. Muy por el contrario, la reclaman por lealtad. El trabajo se queda en el nivel de la descripción. Apenas si se asoma por la ventana del análisis y a la crítica por la rendija. Entrevé el horizonte del marco teórico pero no se atreve a recorrer al menos unos cuantos pasos. A gatas ubica como anexos dos textos de Hernán Emeres y sobre la recreación en el momento actual y como complemento del desarrollo social. Estos con la bibliografía compilada bien pudieron dar lugar a una elaboración teórica. La metodología apropiada pudo ser planteada de manera explícita a fin de justificarla.

No obstante, como se anotó al comienzo, la propuesta es significativa por lo refrescante y sugestiva. Así se posibilita la investigación entendida como proceso: caminar hacia el camino y compartirlo a fin de contribuir a ahorrar a la vez que ganar camino, sin quedarse a la vera del mismo. 